\title{
Issue Highlights-January 2013
}

\section{EXPRESSION OF IMMUNE INHIBITORY RECEPTOR ILT3 IN ACUTE MYELOID LEUKEMIA WITH MONOCYTIC DIFFERENTIATION}

To date, the diagnosis of acute myeloid leukemia (AML) with monocytic differentiation was limited by the lack of highly sensitive and specific monocytic markers (1). Over the last 2 decades, several immunophenotypic markers (lysozyme, elastase, UPA-R, GM-CSF-R, among others) were found to be preferentially expressed by cells belonging to the monocytic lineage, but unfortunately none of them allowed the easy recognition of the pure M5 FAB subvariety of AML (1-5). It is a great pleasure to recall to our readers the pioneering studies performed by Prof Knapp, and later on by the EGIL group, aimed at identifying reliable and reproducible reagents for the detection of granulomonocyte-associated lysosomal protein expression during in vitro and in vivo differentiation of $\mathrm{CD} 34+$ hematopoietic progenitor cells along the myelomonocytic lineages, as well as for the characterization of AML subtypes $(1,5)$. Furthermore, the methodologies used for the cytofluorimetric analysis of intracellular antigens have been the object of investigation by several investigators, with the main aim to improve the reproducibility and comparability of results in multicenter trials $(6,7)$. The main unsolved issue still on the table in this area of investigation continues to be the absence of a reliable test that reliably identifies the monocytic lineage of a malignant transformation; to date neither morphology, cytochemistry, cytogenetics nor molecular biology have satisfactorily achieved this goal. In this issue, the study by Dobrowolska et al. (8) has investigated by flow cytometry the expression of immunoglobulin-like transcript 3 (ILT3) in AML patients and has shown that this new phenotypic marker is expressed in all cases of AML displaying monocytic differentiation but not in AML M1/M2 and M3 subtypes. Based on these findings, ILT3 can be regarded as a highly sensitive and specific marker that distinguishes AML with monocytic differentiation from other types of AML. ILT3 is an immune inhibitory receptor expressed by myelomonocytic cells and at high levels by tolerogenic dendritic cells, making it feasible to be incorporated into the initial diagnostic work-up and monitoring of patients with AML. However, the diagnostic usefulness of this phenotypic marker for the recognition of the monocytic variant of AML needs to be validated in larger series of patients.

\section{INABILITY OF A MONOCLONAL ANTI-LIGHT CHAIN ANTIBODY TO DETECT CLONAL PLASMA CELLS IN MULTIPLE MYELOMA PATIENTS}

There is accumulating evidence in the literature indicating that multicolor flow cytometry is increasingly impor- tant for the diagnosis of minimal residual disease (MRD) assessment of patients with multiple myeloma (MM), although only sporadic reports have proposed consensus techniques for their detection (9-12). However, the literature contains discrepancies in results regarding the exact immunophenotype of normal and neoplastic plasma cells (PCs) and their associated clinical significance. These controversies could be due to methodological problems, such as different gating strategies, the use of different monoclonal antibody clones, different fluorochromes, and the use of different multiparametric staining procedures. It is also important to appreciate that flow cytometry can be an imperfect technique to obtain quantitative information in evaluating PCs in bone marrow because of the frequent physical loss of these cells and/or hemodilution with peripheral blood. To study PC, it is necessary to distinguish between the normal and neoplastic PC immunophenotype. Several studies have reported on the immunophenotype of PCs in MGUS and MM and have examined the immunophenotype of polyclonal PCs (12), thus providing insights regarding the discrimination between normal versus clonal PC. Recent reports have also showed that the immunophenotype of MM PCs can change over time and that normal PCs are heterogeneous in the expression of several immunophenotypic markers such as CD19 and CD56. This implies that for the sensitive, reliable detection of MRD clonality assessment by the detection of cytoplasmic kappa and lambda light chains is advisable (10). In this regard, the data published in this issue of Cytometry by van Velzen et al. (13) provide evidence that the use of polyclonal over monoclonal antibodies is preferred for the detection of intracellular immunoglobulin light chains, thus indicating that the recognition of the monoclonal nature of a given cell proliferation may be a difficult task in selected cases of MM and/or related disorders.

\section{FLOW CYTOMETRIC TESTING OF IMMUNOLOGICAL MARKERS FOR GATING MONOCYTES IN PAROXYSMAL NOCTURNAL HEMOGLOBINURIA}

Paroxysmal nocturnal hemoglobinuria $(\mathrm{PNH})$ is a rare disease clinically characterized by intravascular hemolysis, bone marrow failure, and the high tendency to thrombosis (14). It is caused by a mutation in the phosphatidyl inositol glycan-class A gene leading to partial or complete loss of the cell membrane molecule called glycosyl phosphatidyl inositol (GPI) $(15,16)$. Flow

\footnotetext{
*Correspondence to: Francesco Lanza, Hematology Service, and Stem Cell Transplantation Clinical and Laboratory Unit, University Hospital_Cremona, Italy. E-mail: f.lanza@ospedale.cremona.it DOI 10.1002/cyto.21054

Published online in Wiley Online Library (wileyonlinelibrary.com).
} 
cytometry is the recognized standard method for the detection of GPI-deficient clones in PNH and related disorders. Although the International Clinical Cytometry Society and the International PNH Interest Group have published guidelines for PNH assays (14), data analysis has not been standardized. The majority of current analytical methods use manual gating to enumerate $\mathrm{PNH}$ cells (14-19) although new automated analysis techniques that improve the objectivity of operator input have also been recently developed (19). Gating strategies imply the recognition of the various cell types (monocytes, neutrophil granulocytes, and red blood cells) based on the expression of various phenotypic markers. In this issue, the paper by Dalal et al. (20) demonstrated that CD64-based gating showed more distinct clustering of monocytes than CD33-based gating, allowing for an improved and more objective gating strategy. Interestingly, the number of monocytes in total as well as GPI-deficient monocytes derived from both gating strategies was found to be comparable, thus emphasizing the usefulness of this flow cytometry protocol.

\section{USE OF ANTI-HBF ANTIBODY FOR THE DETECTION AND QUANTIFICATION OF FETOMATERNAL HEMORRHAGE}

The Kleihauer-Betke test (KBT) is the most widely used assay for fetomaternal hemorrhage (FMH) detection in rhesus D negative women $(21,22)$. In this issue of Clinical Cytometry, Pastoret et al. (23) evaluated the performance of flow cytometry for detecting the occurrence of FMH through the use of an anti-HbF antibody (FMH QuikQuant kit). This assay permits the accurate quantification of both fetal and adult erythrocytes with an increased amount of HbF. Based on these findings, it can be postulated that the accurate quantification of fetal cells could be performed in a number of hematological disorders including hemoglobin diseases, hereditary persistence of $\mathrm{HbF}$, and myelodysplastic syndromes. It is finally proposed that the FMH QuikQuant kit is a reliable and highly reproductive flow cytometric method for FMH quantification.

\section{COMPARATIVE STUDY OF GIARDIA DIAGNOSTIC METHODS IN HUMAN FECAL SAMPLES}

Over the last decades, several methods were tried for Giardia detection in stool (24-26). The main aim of this study was to compare the results between standard light microscopy, direct immunofluorescence assay (DIF), and flow cytometry for the detection of Giardia cyst in human stool samples. From this analysis, ElNahas et al. (27) concluded that a direct microscopic examination is reliable in Giardia diagnosis as a first choice test. However, DIF proved to be an excellent technique in clinically suspected cases after negative microscopy. Interestingly, although the flow cytometry method was found to be less sensitive to obtain accurate organism's count, it appeared to be an effective alternative method for the detection of Giardia cysts, especially for large-scale epidemiological studies or extensive surveillance programs as it has the beneficial attribute of speed and does not depend on an experienced microscope viewer.

\section{FLOW CYTOMETRY ASSESSMENT OF REGULATORY T CELL SUBSETS IN HIV-1 INFECTED SUBJECTS}

Regulatory $\mathrm{T}$ cells (Tregs) (also known as suppressor $\mathrm{T}$ cells) are a specialized subpopulation of $\mathrm{T}$ cells that act to suppress immune responses, thereby maintaining homeostasis and self-tolerance. Over the last few years, evidence from both human and animal models has accumulated indicating that Tregs may play a critical role in the pathogenesis of several diseases, suggesting that Tregs may be manipulated toward achieving a desired therapeutic effect (28). Several reports provided evidence that autologous stem cell transplantation for autoimmune diseases may induce immunologic self-tolerance by reprogramming autoreactive $\mathrm{T}$ cells, thus restoring the immune regulatory network. Impairment of Treg development and/or function can precipitate a variety of autoimmune diseases, whereas a higher frequency of Tregs can render the immune system hyporesponsive to pathogens $(29,30)$.

In a recent paper, Grant et al. (31) validated a flow cytometry protocol for the enumeration of FOX-P3 Tregs in clinical samples and saw a signifcant increase in FoxP3 expression in the patients with type 1 diabetes but not in individuals with multiple sclerosis. Because FoxP3 has arisen as the prototypic marker to measure Tregs, along with use of CD127 marker, numerous antibodies have become commercially available. Another subject, which still needs to be addressed in future investigations, is represented by the definition of the immunophenotypic profile of Tregs (29-32). In fact, in addition to CD4, CD25, and Fox-P3 antigens, several other antigenic markers such as CD127, CD45 RA, CD28, CD 152, CD184, and so on have been found to be expressed by different subpopulations of Tregs, suggesting further characterization of these cell types is necessary for a better understanding of the functional role played by the various Tregs cell subsets. Furthermore, instead of intracellular FOXP3 staining, the CD 4+CD25+CD127-phenotype has been proposed as an alternative approach to identify Tregs in clinical samples. However, its use remains controversial in viremic patients. In the article by Saison et al. (33), the objective of the study was to assess the correlation between frequencies of $\mathrm{CD} 4+\mathrm{CD} 25+\mathrm{CD} 127-$ and $\mathrm{CD} 4+$ CD25+FOXP3 + lymphocytes in viremic and matched aviremic HIV-infected patients. From this report, the authors concluded that the CD $4+\mathrm{CD} 25+\mathrm{CD} 127-$ phenotype is a satisfactory and easy-to-perform strategy for the identification of FOXP3 + regulatory $\mathrm{T}$ cells in both viremic and aviremic HIV-1 infected subjects. Thus, it represents a useful tool for monitoring Tregs in clinical research studies based on large cohorts of patients prospectively monitored, including HIVinfected subjects. 


\section{QUANTIFICATION OF MITOCHONDRIAL TOXICITY IN HIV- INFECTED INDIVIDUALS BY QUANTITATIVE PCR COMPARED TO FLOW CYTOMETRY}

A great number of cellular and immunological abnormalities have been described in HIV-infected individuals $(30,34)$. Progress in the development of methodologies to assess antigen-specific $\mathrm{T}$ cells as well as mitochondrial dysfunction has allowed for both qualitative and quantitative damages recognition on HIV-infected cells. Interestingly, the exposure to anti-retroviral treatment was found associated with a diffuse spectrum of metabolic adverse reactions consistent with mitochondrial toxicity.

Several studies indicated that dysfunctional HIV specific cytotoxic T-lymphocytes and mitochondrial alteration exist during disease progression. In this issue, Wagner et al. (35) compared the ratio of mitochondrial to nuclear DNA determined by quantitative PCR to the ratio of mitochondrial to nuclear-encoded proteins by flow cytometry, in peripheral blood mononuclear cells from HIV-infected individuals. This experimental work gave further evidence that a flow cytometry-based protocol may provide reliable results in assessing mitochondrial toxicity in this disease category.

\section{INTER-LABORATORY ASSESSMENT OF FLOW CYTOMETRIC MONOCYTE HLA-DR EXPRESSION IN CLINICAL SAMPLES}

There is accumulating evidence that a diminished expression of human leukocyte antigen-DR on circulating monocytes (mHLA-DR) measured by flow cytometry is considered a reliable indicator of immunosuppression in critically ill patients $(36,37)$. It is also known that monocytes with low HLA-DR expression are known to be unable to mount a proinflammatory response to any subsequent bacterial challenge or to properly present antigens to T cells (37). HLA-DR expression on monocytes has been shown to be predictive of both adverse outcome and septic complications after trauma, surgery, pancreatitis, burn, and septic shock. The objective of the work published in this issue by Demaret et al. (38) was to test, in an interlaboratory clinical study, a standardized protocol for mHLA-DR measurement by flow cytometry. These authors showed the robustness of this standardized flow cytometric protocol for mHLA-DR measurement in multicentric clinical studies, thus providing compelling evidence about the role played by flow cytometry in these clinical settings.

Francesco Lanza* Hematology Service, and Stem Cell Transplantation Clinical and Laboratory Unit University Hospital-Cremona, Italy

\section{LITERATURE CITED}

1. Bene MC, Castoldi G, Knapp W, Ludwig WD, Matutes E, Orfao A, van't Veer MB. Proposals for the immunological classification of acute leukemias. European Group for the Immunological Characterization of Leukemias (EGIL). Leukemia 1995;9:1783-1786.

2. Lanza F, Castoldi GL, Castagnari B, Todd RT III, Moretti S, Spisani S, Latorraca A, Bardi A, Traniello S. Expression and functional role of urokinase-type plasminogen activator receptor (UPA-R) in normal and acute leukemic cells. Br J Haematol 1998;103:110-123.

3. Bellos F, Alpermann T, Gouberman E, Haferlach C, Schnittger S, Haferlach T, Kern W. Evaluation of flow cytometric assessment of myeloid nuclear differentiation antigen expression as a diagnostic marker for myelodysplastic syndromes in a series of 269 patients. Cytometry B Clin Cytom 2012;82B:295-304.

4. Larsen A, Roug A, Just T, Brown G, and Hokland P. Expression of the hMICL in acute myeloid leukemia-A highly reliable disease marker at diagnosis and during follow-up. Cytometry B Clin Cytom 2012;82:3-8.

5. Knapp W, Strobl H, Majdic O. Flow cytometric analysis of cell-surface and intracellular antigens in leukemia diagnosis. Cytometry 1994;18:187-198.

6. Lanza F, Moretti S, Latorraca A, Ferrari L, Castagnari B, Castoldi GL. Cytofluorimetric measurement of cytoplasmic myeloperoxidase by permeabilisation of blood cells with the FACS lysing solution. Cytometry 1996;24:292-295.

7. Lanza F, Latorraca A, Moretti S, Castagnari B, Ferrari L, Castoldi GL Comparative analysis of different permeabilization methods for the flow cytometry measurement of cytoplasmic MPO and lysozyme in normal and leukemic cells. Cytometry 1997;30:1-11

8. Dobrowolska H, Gill KZ, Serban G, Ivan E, Li Q, Qiao W, Suciu-Foca N, Savage D, Alobeid B, Bhagat G, Colovai AI. Expression of immune inhibitory receptor ILT3 in acute myeloid leukemia with monocytic differentiation. Cytometry B Clin Cytom 2013;84B:2129.

9. Frebet E, Abraham J, Genevieve F, Lepelley P, Daliphard S, Bardet V, Amsellem S, Guy J,Mullier F, Durrieu F, Venon M-D, Leleu X, Jaccard A, Faucher J-L, Béné MC, Feuillard, J; for the GEIL (Groupe d'Etude Immunologique des Leucemies) Study Group. A GEIL flow cytometry consensus proposal for quantification of plasma cells: Application to differential diagnosis between MGUS and myeloma. Cytometry B Clin Cytom 2011;80B:176-185.

10. Paiva B, Almeida J, Pérez-Andrés M, Mateo G, Lopez A, Rasillo A, Vidriales M-B, López-Berges M-C, San Miguel JF, Orfao A. Utility of flow cytometry immunophenotyping in multiple myeloma and other clonal plasma cell-related disorders. Cytometry B Clin Cytom 2010;78B:239-252.

11. Johnsen HE, Bøgsted M, Klausen TW, Gimsing P, Schmitz A, Kjærsgaard E, Damgaard T,Voss P, Knudsen LM, Mylin AK, Nielsen JL, Björkstrand B, Gruber A, Lenhoff S, Remes K, Dahl IM, Fogd K, and Dybkær K; Nordic Myeloma Study Group (NMSG) and the Myeloma Stem Cell Network (MSCNET). Multiparametric flow cytometry profiling of neoplastic plasma cells in multiple myeloma. Cytometry B Clin Cytom 2010;78B:338-347.

12. Cannizzo E, Bellio E, Sohani AR, Hasserjian RP, Ferry JA, Dorn ME, Sadowski C, Bucci JJ,Carulli G, Preffer F. Multiparameter immunophenotyping by flow cytometry in multiple myeloma: The diagnostic utility of defining ranges of normal antigenic expression in comparison to histology. Cytometry B Clin Cytom 2010;78B:231-238

13. van Velzen JF, van den Blink D, Bloem AC. Inability of a monoclonal anti-light chain antibody to detect clonal plasma cells in a patient with multiple myeloma by multicolor flow cytometry. Cytometry B Clin Cytom 2013;84B:30-32 (this issue).

14. Hernandez-Campo PM, Almeida J, Sanchez ML, Malvezzi M, Orfao A. Normal Patterns of expression of glycosylphosphatidylinositol-anchored proteins on different subsets of peripheral blood cells: A frame of reference for the diagnosis of paroxysmal nocturnal hemoglobinuria. Cytometry B Clin Cytom 2006;70:71-81.

15. Borowitz MJ, Craig FE, DiGiuseppe JA, Illingworth AJ, Rosse W, Sutherland DR, Wittwer CT, Richards SJ. Guidelines for the diagnosis and monitoring of paroxysmal nocturnal hemoglobinuria and related disorders by flow cytometry. Cytometry B Clin Cytom 2010;78B:211-230.

16. Sutherland DR, Keeney M, Illingworth A. Practical guidelines for the high-sensitivity detection and monitoring of paroxysmal nocturnal hemoglobinuria clones by flow cytometry. Cytometry B Clin Cytom 2012;82B:195-208.

17. Wang A, Pozdnyakova O, Jeffrey L. Detection of paroxymal nocturnal haemoglobinuria clones in patients with myelodisplastic syndromes and related bone marrow diseases, with emphasis on diagnostic pitfalls and caveats. Haematologica 2008;94:29-37

18. Battiwalla M, Hepgur M, Pan D, McCarthy PL, Ahluwalia MS, Camacho SH, Starostik P, Wallace PK. Multiparameter flow cytometry for the diagnosis and monitoring of small GPI-deficient cellular populations. Cytometry B Clin Cytom 2010;78B:348-356.

19. Herbert DJ, Miller DT, Bagwell CB. Automated analysis of flow cytometric data for $\mathrm{CD} 34+$ stem cell enumeration using a probability state model. Cytometry B Clin Cytom 2012;82B:313-318. 
20. Dalal BI, Khare NS. Flow cytometric testing for paroxysmal nocturnal hemoglobinuria: CD64 is better for gating monocytes than CD33. Cytometry B Clin Cytom 2013;84B:33-36.

21. Warang P, Gupta M, Kedar P, Ghosh K, Colah R. Flow cytometric osmotic fragility-An effective screening approach for red cell membranopathies. Cytometry B Clin Cytom 2011;80B:186-190.

22. Subirá D, Uriel M, Serrano C, Castanon S, Gonzalo R, Illan J, Plaza J, Roman A. Significance of the volume of fetomaternal hemorrhage after performing prenatal invasive tests. Cytometry B Clin Cytom 2011;80B:38-42

23. Pastoret C, Le Priol J, Fest T, Roussel M. Evaluation of FMH QuikQuant for the detection and quantification of fetomaternal hemorrhage. Cytometry B Clin Cytom 2013;84B:37-43.

24. Anuar TS, Al-Mekhlafi HM, Ghani MK, Osman E, Yasin AM, Nordin A, Azreen SN, Salleh FM, Ghazali N, Bernadus M, Moktar N. Giardiasis among different tribes of Orang Asli in Malaysia: Highlighting the presence of other family members infected with Giardia intestinalis as a main risk factor. Int J Parasitol 2012;42:871-880.

25. Keserue HA, Füchslin HP, Egli T. Rapid detection and enumeration of Giardia lamblia cysts in water samples by immunomagnetic separation and flow cytometric analysis. Appl Environ Microbiol 2011;77:5420-5427.

26. Barbosa J, Costa-de-Oliveira S, Rodrigues AG, Pina-Vaz C. Optimization of a flow cytometry protocol for detection and viability assessment of Giardia lamblia. Travel Med Infect Dis 2008;6:234-239.

27. El-Nahas HA, Salem DA, El-Henawy A, El-Nimr HI, Abdel Ghaffar HA. Giardia diagnostic methods in human fecal samples: A comparative study. Cytometry B Clin Cytom 2013;84B:44-49.

28. Le NT, Chao N. Regulating regulatory T cells. Bone Marrow Transplant 2007;39:1-9.

29. Lanza F. Towards standardization of Foxp3+ regulatory T cells measurement for clinical use. Cytometry B Clin Cytom 2009;68B:66-68

30. Onlamoon N, Sukapirom K, Polsrila K, Ammaranond P, Pattanapanyasat $\mathrm{K}$. Alteration of CD8 $+\mathrm{T}$ cell effector diversity during HIV-1 infection with discordant normalization in effective antiretroviral therapy. Cytometry B Clin Cytom 2012;82B:35-42.

31. Grant J, Bourcier K, Wallace S, Pan D, Conway A, Seyfert-Margolis V, Wallace PK. Validated protocol for FoxP3 reveals increased expression in Type 1 diabetes patients. Cytometry B Clin Cytom 2009; 76B:69-78.

32. Sattui S, de la Flor C, Sanchez C, Lewis D, Lopez G, Rizo-Patrón E, White AC Jr, Montes M. Cryopreservation modulates the detection of regulatory T cell markers. Cytometry B Clin Cytom 2012;82B:54-58.

33. Saison J, Demaret J, Venet F, Chidiac C, Malcus C, Poitevin-Later F, Tardy JC, Ferry T, Monneret G. CD4+ CD25+ CD127-assessment as a surrogate phenotype for FOXP3 + regulatory $\mathrm{T}$ cells in HIV-1 infected viremic and aviremic subject. Cytometry B Clin Cytom 2013;84B:50-54.

34. Mojumdar K, Vajpayee M, Chauhan NK, Singh A, Singh R, Kurapati S. Altered T cell differentiation associated with loss of CD27 and CD28 in HIV infected Indian individuals. Cytometry B Clin Cytom 2012;82B:43-53.

35. Wagner TA, Lin CH, Tobin NH, Côtè H, Sloan DD, Jerome KR, Frenkel LM. Quantification of mitochondrial toxicity in HIV- infected individuals by quantitative PCR compared to flow cytometry. Cytometry B Clin Cytom 2013;84B:55-58.

36. Riccardi F, Della Porta MG, Rovati B, Casazza A, Radolovich D, De Amici M, Danova M, Langer M. Flow cytometric analysis of peripheral blood dendritic cells in patients with severe sepsis. Cytometry B Clin Cytom 2011;80B:14-21.

37. Roussel M, Gros A, Gacouin A, Le Meur N, Le Tulzo Y, Fest T. Toward new insights on the white blood cell differential by flow cytometry: A proof of concept study on the sepsis model. Cytometry B Clin Cytom 2012;82B:345-352.

38. Demaret J, Walencik A, Jacob MC, Timsit JF, Venet F, Lepape A, Monneret G. Inter-laboratory assessment of flow cytometric monocyte HLA-DR expression in clinical samples. Cytometry B Clin Cytom 2013;84B:59-62. 